\title{
Test Yourself Question: A 38-year-old male presenting with a 1-year history of medial right knee pain
}

\author{
Susan Hesni ${ }^{1} \cdot$ Daniel Lindsay $^{2} \cdot$ Asif Saifuddin $^{1}$
}

Received: 22 December 2021 / Revised: 22 December 2021 / Accepted: 17 January 2022 / Published online: 24 January 2022 (C) ISS 2022

\section{Question}

A 38-year-old male presenting with a 1-year history of medial right knee pain. There was no previous trauma (Figs. 1, 2, and 3).

The diagnosis can be found at https://doi.org/10.1007/s00256-02203998-7

Susan Hesni

susan.hesni@nhs.net

1 Department of Radiology, Royal National Orthopaedic Hospital (RNOH), Brockley Hill, Stanmore HA7 4LP, UK

2 Department of Histopathology, Royal National Orthopaedic Hospital (RNOH), Brockley Hill, Stanmore HA7 4LP, UK 
Fig. 1 MRI of the right knee. a Sagittal T1W TSE, b coronal fat suppressed PDW FSE, and c axial fat suppressed post-contrast T1W FSE MR images
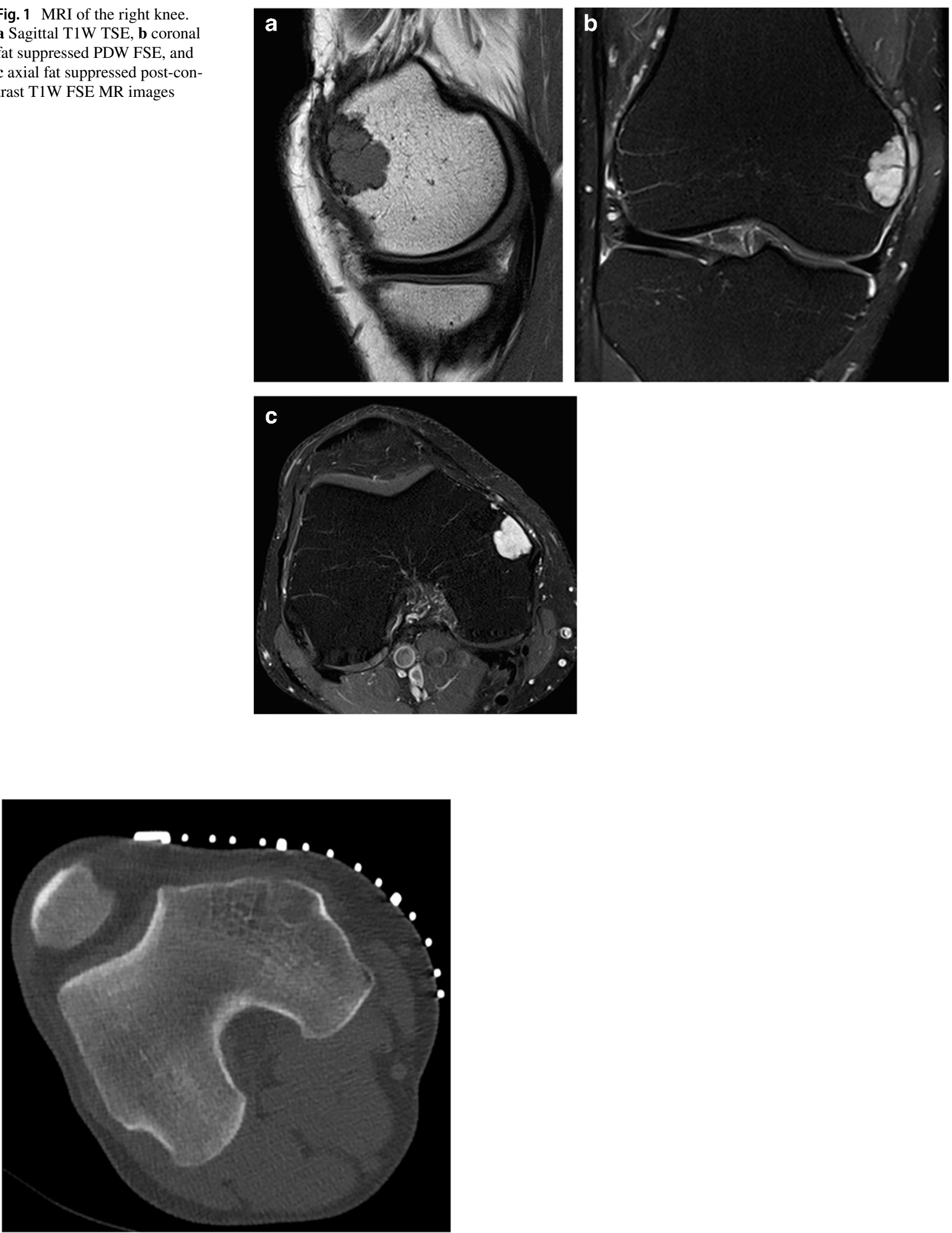

Fig. 2 CT obtained at the time of biopsy 

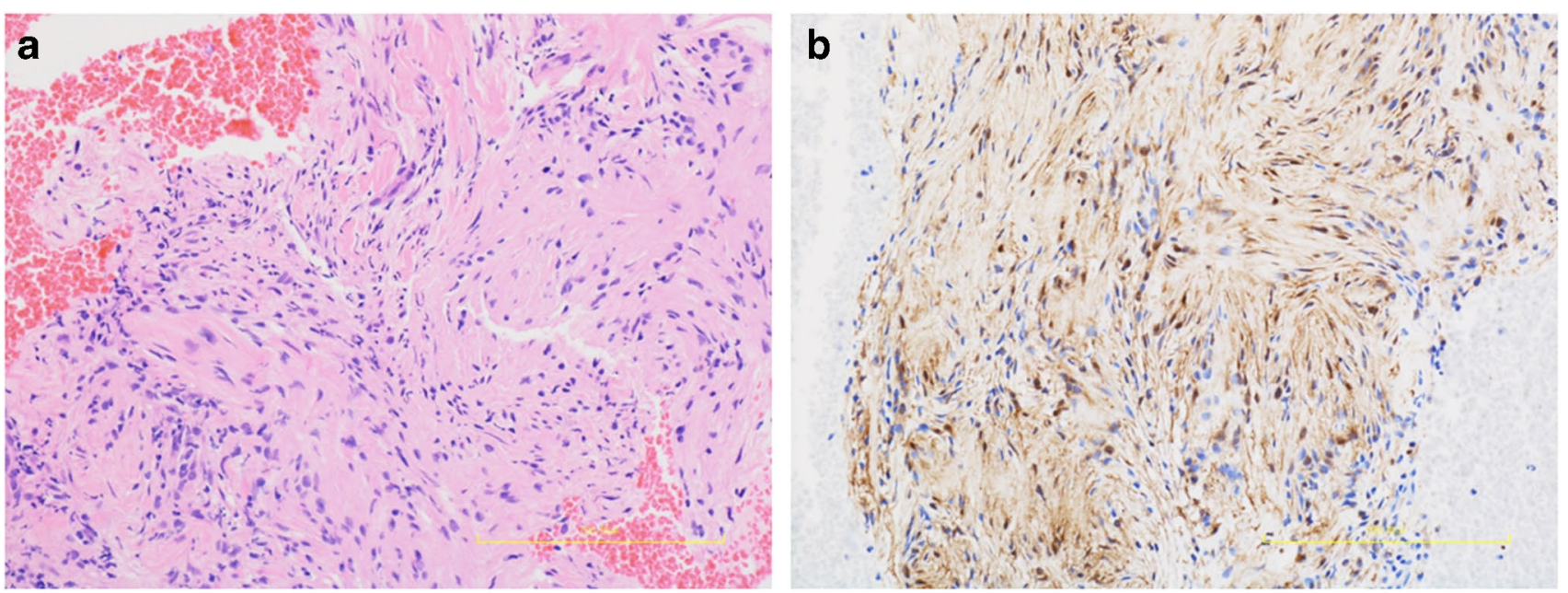

Fig. 3 Histology. a H\&E x X magnification. b Immunohistochemistry for S100

\section{Declarations}

Conflict of interest The authors declare that they have no conflicts of interest.

Publisher's note Springer Nature remains neutral with regard to jurisdictional claims in published maps and institutional affiliations. 